\title{
Auditory Input to CNS Is Acquired Coincidentally with Development of Inner Ear after Formation of Functional Afferent Pathway in Zebrafish
}

\author{
Masashi Tanimoto, ${ }^{1}$ Yukiko Ota, ${ }^{1}$ Kazuki Horikawa, ${ }^{2}$ and Yoichi $0 \mathrm{da}^{1}$ \\ ${ }^{1}$ Division of Biological Science, Graduate School of Science, Nagoya University, Nagoya 464-8602, Japan, and 2Nikon Imaging Center, Hokkaido University, \\ Hokkaido 001-0020, Japan
}

\begin{abstract}
Auditory perception in vertebrates depends on transduction of sound into neural signals in the inner ear hair cells (HCs) and on transmission of these signals to the brain through auditory (VIIIth) nerve afferents. To investigate the developmental acquisition of auditory inputs by the CNS, we have electrophysiologically and morphologically examined the process of acquisition of auditory responsiveness by zebrafish macular HCs and the Mauthner cells (M-cells) in vivo. The M-cells are a paired large reticulospinal neurons in the hindbrain; they receive direct inputs from the VIIIth nerve afferents and initiate an acoustic startle response. Whole-cell recordings from the M-cells showed that sound-evoked postsynaptic currents were first observed around $40 \mathrm{~h}$ postfertilization (hpf); during subsequent development, onset latency decreased and amplitude increased. The appearance and development of microphonic potentials in the inner ear coincided with those of the acoustic responses of the M-cell, whereas the functional auditory circuits from the macular HCs to the $\mathrm{M}$-cell were already formed at $27 \mathrm{hpf}$. These results suggest that the functional maturation of inner ear after formation of the auditory pathway is a critical process in the acquisition of auditory inputs by CNS neurons.
\end{abstract}

\section{Introduction}

The vertebrate sensory patches known as the maculae, the cristae, and the organ of Corti detect body motion and sound. Macular organs, which contain receptor hair cells (HCs) coupled to crystalline deposits of otoconia (also known as otoliths), are important for sensing linear acceleration and gravity; they also contribute to hearing in lower vertebrates, such as fish and frogs (Popper and Fay, 1993).

Sound-evoked auditory responsiveness in brain neurons is acquired well after the morphological formation of the afferent pathway in mammals and birds (see Discussion). Yet it remains unknown which locus in the pathway has not developed enough functionally to allow transmission from the ear to the recipient CNS neurons. We used zebrafish as a model system to investigate this issue. Zebrafish and goldfish use auditory information effectively to escape quickly from sudden stimuli or predators by firing the Mauthner cells (M-cells) in the hindbrain (Zottoli, 1977; Burgess and Granato, 2007; Kohashi and Oda, 2008). In adult goldfish, it has been established morphologically as well as elec-

\footnotetext{
Received 0ct. 24, 2008; revised Jan. 1, 2009; accepted Jan. 23, 2009.

This work was supported by a Grant-in-Aid for Scientific Research from the Ministry of Education, Culture, Sports, Science, and Technology of Japan (17023029 and 18300134 to Y.0.) and by the Zebrafish National BioResource Project of Japan. We thank Yasuko Sato and Dr. Hiroyuki Takeda for providing the Tol026 and Tol056 transgenic zebrafish, and Dr. Hitoshi Okamoto for providing the $\alpha$-actin:GFP and the Tg(zCREST2-is/1:GFP) transgenic zebrafish. We are very grateful to Dr. Teresa Nicolson for providing antibodies against Vglut3 and Ribeye b, Dr. Shin-ichi Higashijima for technical instruction, and Drs. Harunori Ohmori, Shin Takagi, and Hiromi Hirata for helpfu discussions.

Correspondence should be addressed to Dr. Yoichi Oda, Division of Biological Science, Graduate School of Science, Nagoya University, Furo-cho, Chikusa, Nagoya 464-8602, Japan. E-mail: oda@bio.nagoya-u.ac.jp. DOI:10.1523/JNEUROSCI.5530-08.2009

Copyright $\odot 2009$ Society for Neuroscience $\quad$ 0270-6474/09/292762-06\$15.00/0
}

trophysiologically that the M-cell is directly innervated by the ipsilateral VIIIth nerve afferents (Furshpan, 1964; Nakajima, 1974; Lin and Faber, 1988; Nakayama and Oda, 2004; Szabo et al., 2006, 2007). In zebrafish, sound-induced postsynaptic potentials have been recorded in the adult M-cell (Hatta and Korn, 1998), and the earliest contact of the VIIIth nerve afferents with the M-cell occurs at $23 \mathrm{~h}$ postfertilization (hpf) (Kimmel et al., 1990). How does the $\mathrm{M}$-cell acquire auditory responsiveness during development? Neither the process of the VIIIth afferents' innervation of the macular HCs nor the development of auditory responsiveness in the M-cell and macular HCs has yet been elucidated. Here, we investigated these issues through in vivo whole-cell recordings from the M-cells, extracellular recordings of macular HC activity, and morphological investigations of the VIIIth nerve afferents from the macular HCs to the M-cells in zebrafish embryos and larvae.

\section{Materials and Methods}

Animals. We used four strains of transgenic zebrafish: $\alpha$-actin:GFP (Higashijima et al., 1997), $\operatorname{Tg}(z$ CREST2-isl1:GFP) (Uemura et al., 2005), Tol026, and Tol056. Tol026 and Tol056, which were generated by K. Horikawa, Y. Sato, and H. Takeda (University of Tokyo, Tokyo, Japan) using the Tol2 transposon-mediated enhancer trap technique (Kawakami, 2005), express green fluorescent protein (GFP) in the $\mathrm{M}$-cells. Embryos and larvae were reared at $28.5^{\circ} \mathrm{C}$ and staged according to standard procedures.

Electrophysiological recordings. Electrophysiological experiments were performed at $26-28^{\circ} \mathrm{C}$ on transgenic zebrafish embryos and larvae $(\alpha-$ actin:GFP for 27-34 hpf, Tol026 for 34-60 hpf, Tol056 for $>60 \mathrm{hpf}$ ). All procedures complied with the guidelines stipulated by the Nagoya University Committee on Animal Research. Preparations were made as de- 
A
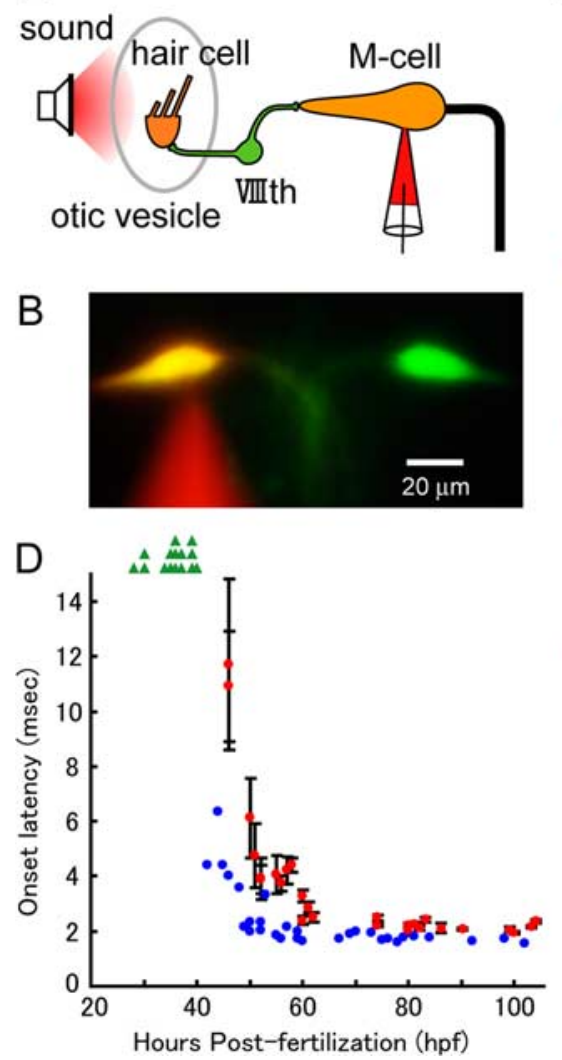

Figure 1. Acquisition and development of sound-evoked PSCs in the M-cell. A, Principal auditory circuits consist of macular HCS, VIIIth nerve afferents, and the M-cell. Sound-evoked PSCs were recorded in the M-cell using the in vivo whole-cell clamp technique. $\boldsymbol{B}$, Dorsal view of the whole-cell recording of one of the paired, GFP-expressing M-cells (green) with a recording pipette filled with Alexa Fluor 594 (red) in a Tol056 transgenic larva at 105 hpf. C, Acquisition and development of PSCs evoked by sound stimuli ( $500 \mathrm{~Hz}, 98 \mathrm{~dB}$ SPL) in the M-cells of embryos and larvae at denoted ages. PSCs were never observed before $40 \mathrm{hpf}$, as also shown in $\boldsymbol{D}$ (15 cells, green triangles). At $46 \mathrm{hpf}$, only small PSCs with long and unstable onset latency, and sometimes with failures (red and black traces, respectively), were obtained. Arrowheads and asterisks indicate the initial transient and following slow components of the developed PSCs, respectively. Holding potential, $-74 \mathrm{mV}$. D, Onset latency of the sound-evoked PSCS was calculated from 10 responses and was plotted against hours postfertilization ( 26 cells, mean \pm SD, red circles and black bars). The responses appeared after $40 \mathrm{hpf}$; their mean latency and fluctuation decreased until $60 \mathrm{hpf}$. Onset latency of the microphonic potentials was also plotted (blue circles, see Results).

scribed previously (Kimura et al., 2006) with some modifications. Embryos and larvae were temporarily anesthetized and immobilized in $0.02 \%$ tricaine methanesulphonate (MS-222; Sigma-Aldrich) and $1 \mathrm{~mm}$ D-tubocurarine (Sigma-Aldrich) for $\sim 20 \mathrm{~min}$. Fish were then rinsed and pinned on a dish filled with extracellular solution containing (in mM) 134 $\mathrm{NaCl}, 2.9 \mathrm{KCl}, 1.2 \mathrm{MgCl}_{2}, 2.1 \mathrm{CaCl}_{2}, 10 \mathrm{HEPES}$, and 10 glucose, adjusted to $\mathrm{pH} 7.8$ with $\mathrm{NaOH}$. Whole-cell recordings from the M-cells were obtained with a MultiClamp 700B amplifier (Molecular Devices). Patchclamp electrodes (pipette resistance 3-6M $\Omega$ ) were filled with intracellular solution containing (in $\mathrm{mM}$ ) $119 \mathrm{~K}$-gluconate, $6 \mathrm{KCl}, 2 \mathrm{MgCl}_{2}, 10$ HEPES, 10 EGTA, and $4 \mathrm{Na}_{2} \mathrm{ATP}$, at $290 \mathrm{mOsm}$, and adjusted to $\mathrm{pH} 7.2$ with $\mathrm{KOH}$. The measured liquid junction potentials, which we corrected for, were $14 \mathrm{mV}$. Voltage errors were minimized with $>80 \%$ series resistance compensation, and membrane currents were sampled at $50 \mathrm{kHz}$. The M-cells were labeled with $0.005 \%$ Alexa Fluor 594 hydrazide (Invitrogen) in the intracellular solution. Fluorescent images were acquired with a CCD camera (CoolSNAP, Photometrics). Sound stimuli were applied in air from a loudspeaker positioned $45 \mathrm{~cm}$ lateral to the fish (reference sound pressure $\left.=10^{-3} \mathrm{~Pa}\right)($ Oda et al., 1998). This study used data from the M-cells with resting membrane potentials more negative than $-65 \mathrm{mV}$ and analyzed them with Clampfit 10.2 software (Molecular Devices).

To record microphonic potentials, a recording micropipette was inserted into the otic vesicle (OV) (Corey et al., 2004; Obholzer et al., 2008;
Prober et al., 2008). To apply imperative mechanical stimulation to the macular HCs, a piezoelectric probe or micropipette filled with extracellular solution was positioned adjacent to the otoliths. We reduced vibration of the recording pipette by holding it with a microprobe during sound, puff, or piezoelectric stimulation. To block mechanotransduction channels pharmacologically (Gale et al., 2001), FM1-43 (Invitrogen) dissolved at $40 \mu \mathrm{M}$ was applied into the OV through a micropipette.

In vivo imaging and immunohistochemistry. The VIIIth nerve afferent pathway was observed in $\alpha$-actin:GFP or $\operatorname{Tg}(z C R E S T 2-i s l 1: G F P)$ embryos expressing GFP in the VIIIth ganglion neurons. Macular HCs were labeled with FM1-43 at $40 \mu \mathrm{M}$ injected into the OV. Presynaptic molecules at afferent synapses in the HCs were labeled with rabbit polyclonal antibodies against Danio rerio vesicular glutamate transporter 3 (Vglut3) and Ribeye b (provided by Teresa Nicolson, Oregon Health \& Science University, Portland, OR) (Obholzer et al., 2008) as primary antibodies, and detected with Alexa 488- or Alexa 555-conjugated anti-rabbit IgG at 1:2000 dilution. Whole embryos were mounted in agar for confocal imaging of the auditory pathway (FV300, Olympus).

\section{Results}

Acquisition and development of soundevoked response in the $M$-cell

We succeeded in whole-cell recordings from the M-cell in intact embryonic and larval zebrafish (Fig. 1A,B) (27-105 hpf). The larval M-cell (62-105 hpf) showed significant inward currents in response to tone bursts at $500 \mathrm{~Hz}$ [98 dB sound pressure level (SPL)] (Fig. 1C,D). Each inward postsynaptic currents (PSCs) consists of an initial fast component with short and stable onset latency (Fig. 1C, arrowheads) and subsequent slow components (Fig. $1 C$, asterisks). This response was not obtained in embryos before $40 \mathrm{hpf}$ ( 15 cells), although loud sound stimuli with various frequencies $(100-1500 \mathrm{~Hz})$, amplitudes $(<105 \mathrm{~dB})$, and durations (10-100 ms) were applied. At $46 \mathrm{hpf}$, inward currents were elicited, but these exhibited long and unstable onset latency, and sometimes failed. As shown in Figure $1 D$, the decrease in onset latency of acoustically evoked responses with age indicates that remarkable development in transduction and/or transmission properties continues until $60 \mathrm{hpf}$. Hence, it is suggested that the M-cell starts detecting sounds around $40 \mathrm{hpf}$ and that the auditory afferent system develops the ability to transmit auditory information to the M-cell during the subsequent half-day.

Morphological establishment of afferent circuits to the M-cell Previous morphological studies on the zebrafish inner ear have shown that two otoliths appear inside the OV by $18-18.5 \mathrm{hpf}$ (Riley et al., 1997), and that macular HCs begin to differentiate around $24 \mathrm{hpf}$ at the sites of these otoliths (Haddon and Lewis, 1996; Omori and Malicki, 2006). In addition, the central projection of the VIIIth nerve to the M-cell is first observed at $23 \mathrm{hpf}$ (Kimmel et al., 1990), as we have also shown in an $\alpha$-actin:GFP transgenic zebrafish (supplemental Fig. 1, available at www. 
jneurosci.org as supplemental material). Some explanation for the delay in onset of acoustically evoked PSCs in the M-cell (at 39-46 hpf) is, therefore, necessary. One possibility is that peripheral projections of the VIIIth nerve afferents do not reach the macular HCs until 40 hpf. However, Figure $2 A-F$ shows peripheral processes of the VIIIth ganglion neurons, expressing GFP in $T g(z C R E S T 2-i s l 1: G F P)$ or $\alpha$-actin: GFP transgenic zebrafish, appearing to contact the basal end of both anterior and posterior macular HCs, which were specifically labeled with fluorescent dye FM143 , at 27 hpf. Furthermore, immunohistochemistry with antibodies against both Vglut3 and Ribeye b (Obholzer et al., 2008) revealed immunoreactivity at the basal end of both anterior and posterior macular HCs at this stage (Fig. 2G-L). In the following stage, macular HCs immunoreactive for Vglut3 and Ribeye b increased in number, as described previously (Haddon and Lewis, 1996; Obholzer et al., 2008). These observations suggest that both VIIIth nerve projections from macular HCs to the M-cell and afferent synapses at HCs have been formed morphologically before the M-cell receives its first soundevoked PSCs.

\section{Acquisition and development of microphonic potentials}

Mechanotransduction of sound-induced vibrations into electrical signals in the $\mathrm{HCs}$ is the first step in auditory processing. Sound-evoked microphonic potentials in the OV showed that typical negative-going potentials appeared at twice the stimulus frequency after $40 \mathrm{hpf}$ (Fig. $3 A, B$ ). As the fish grew, response amplitude increased and onset latency decreased (Figs. $3 B$, circles; $1 D$, blue circles). Sound-evoked microphonic potentials were never observed after the application of FM1-43, a permeant blocker of mechanotransduction of HCs (Gale et al., 2001), into the OV (Fig. $3 A, B$, triangles). Thus, the acquisition of $\mathrm{HC}$ responsivity to sound coincides with the onset of sound-evoked responses in the M-cell, suggesting the possibility that the acquisition of acoustic responses by the M-cell depends on the functional maturation of the inner ear.

\section{Immature but functional auditory afferents activated before} the M-cell exhibits sound-evoked responses

Although microphonic potentials were never observed before 40 hpf (Fig. 3A,B), the HCs at $27 \mathrm{hpf}$ were labeled by FM1-43 that entered via mechanotransduction channels (Fig. 2A-D) (Meyers et al., 2003). Therefore, we hypothesized that the HCs have some mechanosensitivity at this early stage, but cannot yet transduce sound-evoked vibrations into electrical signals effectively. We
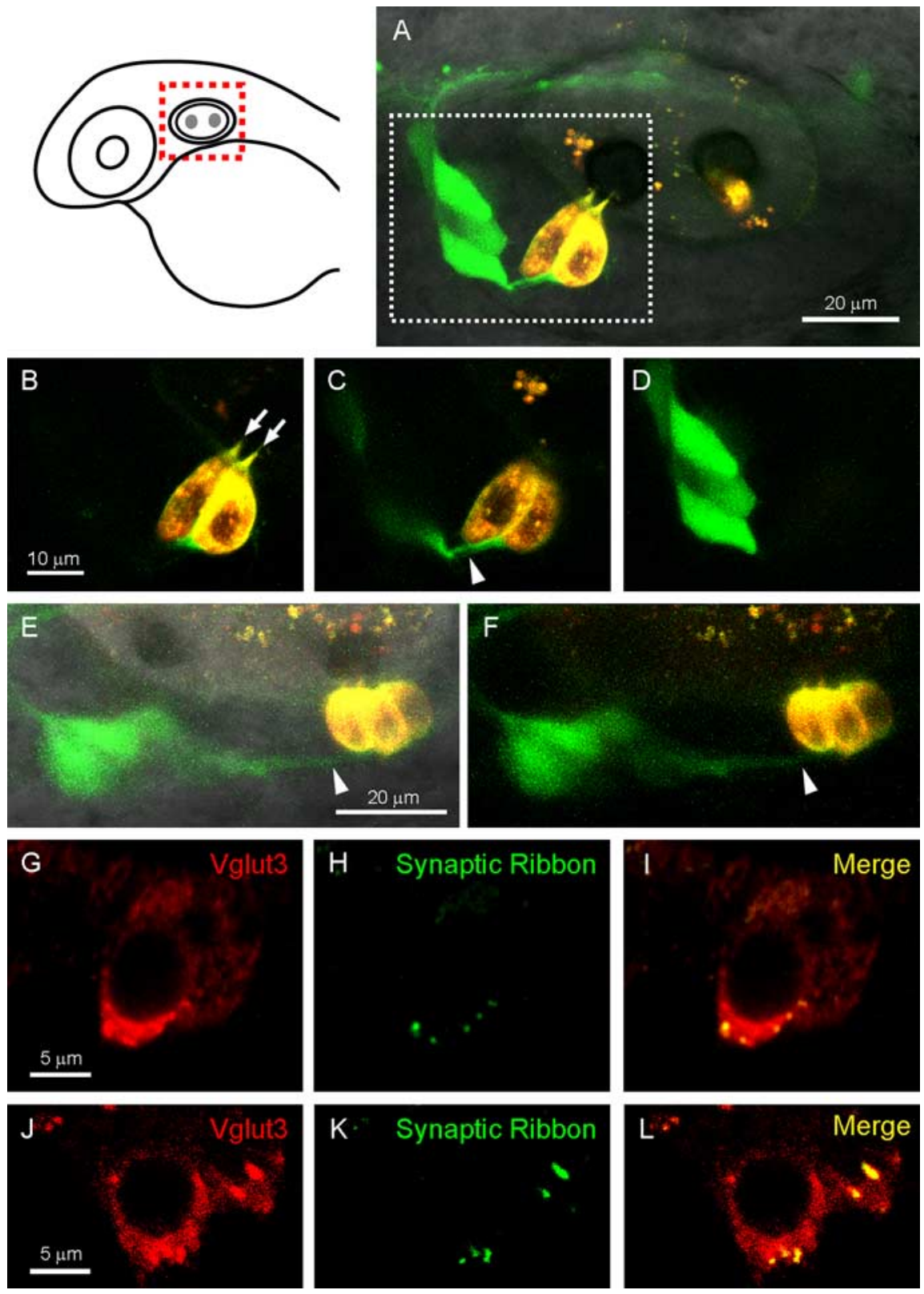

Figure 2. Early projections of the VIIIth nerves to the macular hair cells. $\boldsymbol{A}-\boldsymbol{D}$, Stacked image $(\boldsymbol{A})$ and the composing serial optical planes (B-D) of the lateral part of the $0 \mathrm{~V}$ in a $\mathrm{Tg}$ (ZCREST2-is/1:GFP) embryo at 27 hpf. Dotted square in $(\boldsymbol{A})$ is highlighted in $(\boldsymbol{B}-\boldsymbol{D}) . \boldsymbol{B}, \boldsymbol{C}$, Anterior macular HCs with cilia (arrows) labeled with FM1-43 were contacted at the base by peripheral axons of the VIIIth ganglion neurons (arrowhead). $\boldsymbol{D}$, The somata of at least three VIIIth ganglion neurons expressing GFP. $E, F, A s$ in $\boldsymbol{A}-\boldsymbol{D}$, peripheral axons of VIIIth ganglion neurons in an $\alpha$-actin:GFP embryo (arrowhead) contacted the base of posterior macular HCS labeled with FM1-43 at $27 \mathrm{hpf}$. These images represent a more medial region of the $0 \mathrm{~V}$ than that shown in A-D. G-I, Immunostaining of anterior $(\mathbf{G}-\boldsymbol{I})$ and posterior $(\boldsymbol{J}-\boldsymbol{L})$ macular $\mathrm{HC}$ of wild-type embryos at $27 \mathrm{hpf}$ with $\operatorname{Vglut} 3(\boldsymbol{G}, \boldsymbol{J})$ and Ribeye $b(\boldsymbol{H}, \boldsymbol{K})$ antibodies, and merged images $(I, L)$. Both Vglut 3 and Ribeye $b$ immunofluorescence localized at the basal end of the hair cells. Images in $\mathbf{G}-\boldsymbol{I}$ and $\boldsymbol{J}-\boldsymbol{L}$ were obtained from the same single confocal section, respectively. Anterior is to the left and dorsal is up. Scale bars in $\boldsymbol{B}, \boldsymbol{E}, \boldsymbol{G}$, and $\boldsymbol{J}$ were applied to $\boldsymbol{C}$ and $\boldsymbol{D}, \boldsymbol{F}, \boldsymbol{H}$ and $\boldsymbol{I}$, and $\boldsymbol{K}$ and $\boldsymbol{L}$, respectively.
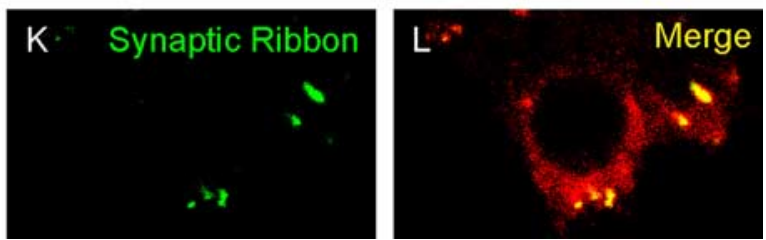

examined this possibility by applying an imperative mechanical stimulation. A water puff to the otolith evoked negative-going potentials before $40 \mathrm{hpf}$ ( 4 fish, 27-39 hpf) (Fig. $4 \mathrm{~A}$ ). In addition, step displacement of the otolith by a piezoelectric probe elicited a transient negative potential at the early stage (4 fish, 27-38 hpf) (Fig. 4C). These responses were also completely blocked by applying FM1-43 into the OV (3 fish) (Fig. 4B,D). These data support the hypothesis described above.

Furthermore, the imperative stimuli to the macular HCs 
A
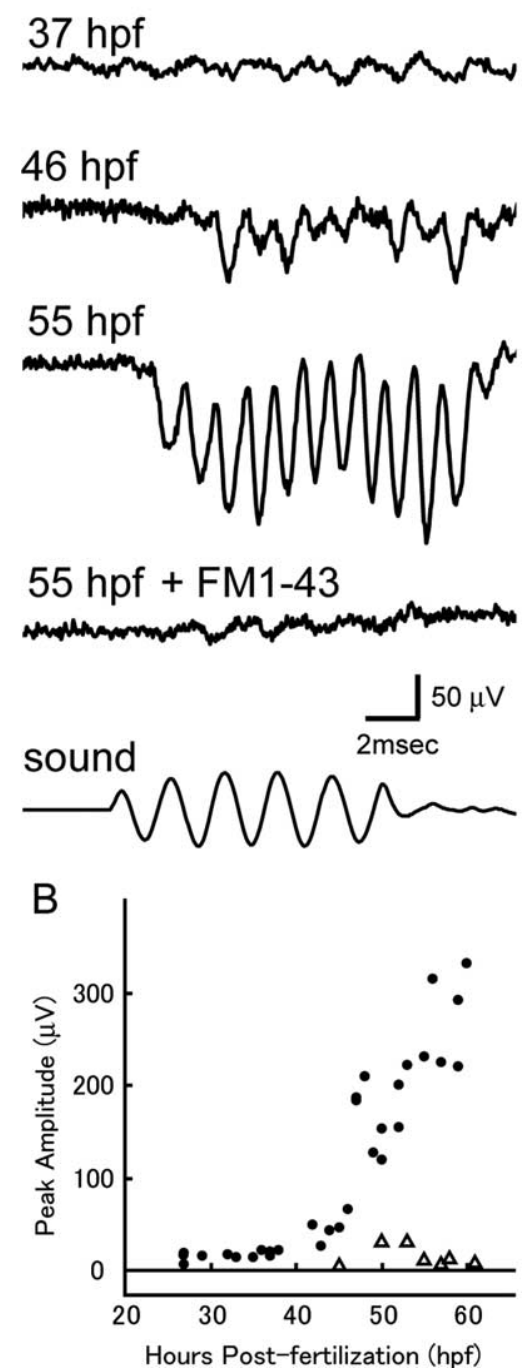

Figure 3. Acquisition and development of microphonic potentials. $\boldsymbol{A}$, Microphonic potentials in response to sound stimuli $(500 \mathrm{~Hz}, 98 \mathrm{~dB}$ SPL, bottom trace) in embryos and larvae. Negative-going potentials were observed at $46 \mathrm{hpf}$ and developed during the following stage; responses were never observed before $40 \mathrm{hpf}$. The responses were blocked by FM1- 43 applied into the OV (55 hpf + FM1-43). Averaged traces of 40 consecutive responses. $\boldsymbol{B}$, Peak amplitudes of the averaged microphonic potentials plotted against hours postfertilization. Potentials appeared after $40 \mathrm{hpf}$ and increased in amplitude as development proceeded (filled circles). The potentials were blocked by FM1- 43 application (open triangles).

evoked obvious PSCs in the M-cells before 40 hpf (9 fish) (Fig. $4 F)$. The responses were specifically depressed by FM1-43 application into the OV (Fig. 4G). These results suggest that the VIIIth nerve afferents from the macular HCs to the M-cell were at least partly functional before the M-cell began to acquire acoustic responses. Together with the data from the previous paragraph, this suggests that the timing of the acquisition of sound-evoked response in the M-cell depends on the functional maturation of the inner ear, including the developmental improvement of sensitivity of the macular HCs to sound.

\section{Discussion}

It has been shown in rats and mice that acoustically evoked activity in the brainstem neurons is elicited only after 10-12 postnatal days (Mikaelian and Ruben, 1965; Geal-Dor et al., 1993), although the afferent circuits from cochlear HCs to the cochlear nucleus are morphologically formed before birth (Lenoir et al., 1980; Neises et al., 1982; Sobkowicz et al., 1982; Limb and Ryugo, 2000). A similar delay in the onset of sound responsivity has been shown in chick embryos (Jhaveri and Morest, 1982; Whitehead and Morest, 1985; Jones et al., 2006). Yet the key factor in acquisition of auditory responsiveness remains unidentified.

The present study shows that, as in these higher vertebrates, the auditory responses of the M-cell in zebrafish, mediated by a direct pathway through the VIIIth nerve afferents, are first observed well after the formation of these afferents, at $\sim 40 \mathrm{hpf}$ (Fig. 1 ), whereas the appearance of macular HCs, the formation of the afferent synapses at the HCs, and the projection of the VIIIth nerve from macular HCs to the M-cell all occur before $27 \mathrm{hpf}$ (Fig. 2). Although the synaptic transmission between the VIIIth nerve afferents and the macular HCs or the M-cell remains to be elucidated directly, our discovery that displacement of the otoliths by imperative mechanical stimulation evoked PSCs in the M-cell before the acquisition of sound-induced PSCs (Fig. 4), probably through opening of mechanotransducer channels at the macular HCs, strongly suggests that the auditory afferent pathway is already functional at this early stage. Furthermore, recordings of the microphonic potentials clearly demonstrate that the onset of sound-evoked response in the M-cell coincides with the acquisition of responsivity of the macular HCs to sound (Fig. 3). But what is the key component in the acquisition of this responsivity?

Zebrafish are otophysan hearing specialists; they have a second auditory system involving the swimbladder (Canfield and Eaton, 1990) and Weberian ossicles (Popper and Fay, 1999). Development of these peripheral auditory structures and other macular organs occurs after the onset of auditory perception (Kimmel et al., 1995; Bang et al., 2001; Bever and Fekete, 2002; Bird and Mabee, 2003), and may contribute to the improvement of sound sensitivity.

An increase in the number of macular HCs is unlikely to directly explain the appearance and development of the microphonic potentials, because it has been shown that the number of macular HCs increases between 24 and $42 \mathrm{hpf}$, then remains at a plateau until 60 or 70 hpf (Haddon and Lewis, 1996). Furthermore, imperative mechanical stimulation to the otoliths obviously elicited microphonic potentials in the OV and PSCs in the $\mathrm{M}$-cell at $27 \mathrm{hpf}$, that is, during the early stage when only a few macular HCs were present (Figs. 2, 4).

In contrast, expression of a mechanotransduction channel may account for the acquisition of acoustic response in the macular HCs. It has previously been demonstrated that expression of $\operatorname{trpn} 1$ (nompC) encoding a transient receptor potential channel is critical for HC mechanotransduction and induction of acoustically evoked escape behavior in zebrafish (Sidi et al., 2003), although in Xenopus the channel localizes at the tip of a kinocilium (Shin et al., 2005). $\operatorname{trpn} 1$ is expressed at $48 \mathrm{hpf}$ in the maculae organ of zebrafish larvae (Sidi et al., 2003); this contrasts with (1) the early formation of the functional auditory afferent pathway (Figs. 2, 4) including the appearance of the macular HCs and the hair bundles (Fig. 2) (Haddon and Lewis, 1996; Riley et al., 1997; Haddon et al., 1998; Omori and Malicki, 2006), (2) the early expression of mechanotransduction-related molecules (Ernest et al., 2000; Seiler et al., 2004, 2005; Söllner et al., 2004), and (3) the early formation of presynaptic molecules responsible for synaptic transmission to the VIIIth nerve afferents (Fig. 2) (Sidi et al., 2004; Obholzer et al., 2008).

Detection of sound vibration depends on relative displace- 
ment between the otoliths and the underlying macular HCs due to difference in inertia. It has been shown previously that the otoliths appear at $19.5 \mathrm{hpf}$ and develop morphologically thereafter (Haddon and Lewis, 1996). Thus, the kinematic improvement of the inner ear structure may also contribute to the refinement of the sensitivity of the macular HCs in transducing sound into electrical signals.

The data obtained in the present in vivo study have elucidated the developmental acquisition of auditory inputs by the CNS in zebrafish. Based on our results, it will now be possible to further elucidate the early development of vertebrate sensory systems, in physiological and morphological terms as well as from a genetic approach.

\section{References}

Bang PI, Sewell WF, Malicki JJ (2001) Morphology and cell type heterogeneities of the inner ear epithelia in adult and juvenile zebrafish (Danio rerio). J Comp Neurol 438:173-190.

Bever MM, Fekete DM (2002) Atlas of the developing inner ear in zebrafish. Dev Dyn 223:536-543.

Bird NC, Mabee PM (2003) Developmental morphology of the axial skeleton of the zebrafish, Danio rerio (Ostariophysi: Cyprinidae). Dev Dyn 228:337-357.

Burgess HA, Granato M (2007) Sensorimotor gating in larval zebrafish. J Neurosci 27:4984-4994.

Canfield JG, Eaton RC (1990) Swimbladder acoustic pressure transduction initiates Mauthnermediated escape. Nature 347:760-762.

Corey DP, García-Añoveros J, Holt JR, Kwan KY, Lin SY, Vollrath MA, Amalfitano A, Cheung EL, Derfler BH, Duggan A, Géléoc GS, Gray PA, Hoffman MP, Rehm HL, Tamasauskas D, Zhang DS (2004) TRPAl is a candidate for the mechanosensitive transduction channel of vertebrate hair cells. Nature 432:723-730.

Ernest S, Rauch GJ, Haffter P, Geisler R, Petit C, Nicolson T (2000) Mariner is defective in myosin VIIA: a zebrafish model for human hereditary deafness. Hum Mol Genet 9:2189-2196.

Furshpan EJ (1964) "Electrical transmission" at an excitatory synapse in a vertebrate brain. Science 144:878-880

Gale JE, Marcotti W, Kennedy HJ, Kros CJ, Richardson GP (2001) FM1-43 dye behaves as a permeant blocker of the hair-cell mechanotransducer channel. J Neurosci 21:7013-7025.

Geal-Dor M, Freeman S, Li G, Sohmer H (1993) Development of hearing in neonatal rats: air and bone conducted ABR thresholds. Hear Res 69:236-242.

Haddon C, Lewis J (1996) Early ear development in the embryo of the zebrafish, Danio rerio. J Comp Neurol 365:113-128.

Haddon C, Jiang YJ, Smithers L, Lewis J (1998) Delta-Notch signalling and the patterning of sensory cell differentiation in the zebrafish ear: evidence from the mind bomb mutant. Development 125:4637-4644.

Hatta K, Korn H (1998) Physiological properties of the Mauthner system in the adult zebrafish. J Comp Neurol 395:493-509.

Higashijima S, Okamoto H, Ueno N, Hotta Y, Eguchi G (1997) Highfrequency generation of transgenic zebrafish which reliably express GFP in whole muscles or the whole body by using promoters of zebrafish origin. Dev Biol 192:289-299.

Jhaveri S, Morest DK (1982) Sequential alterations of neuronal architecture
$B$

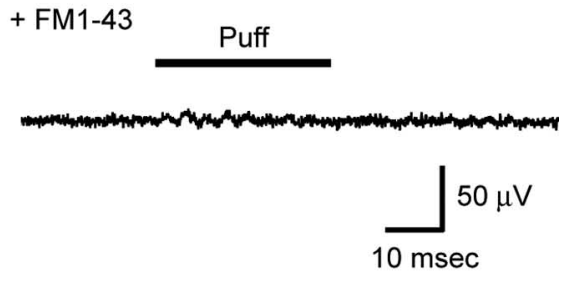

E

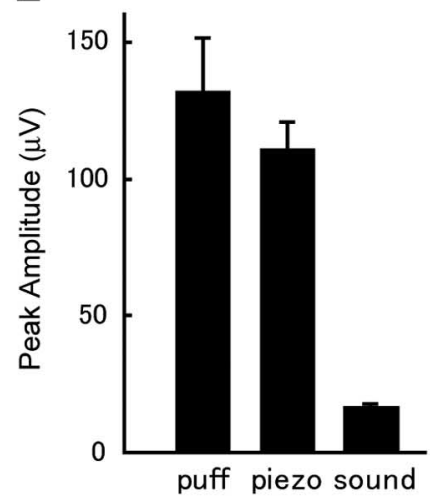

$\mathrm{G}$

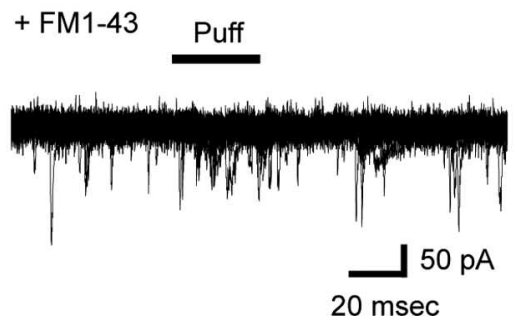

Figure 4. Imperative mechanical stimulation elicited microphonic potentials in the OV and PSCs in the M-cell before $40 \mathrm{hpf} . \boldsymbol{A}$ A water puff to the otolith (black bars above) induced a negative-going potential in the OV of a $27 \mathrm{hpf}$ embryo. $\boldsymbol{B}$, The potential was 作 . The mechanotransduction responsewasblocked byFM1-43

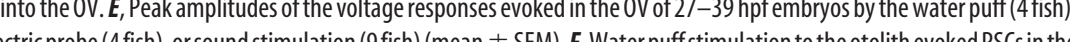
$\mathrm{M}$-cell at $27 \mathrm{hpf}$. G, The PSCs obtained in $\boldsymbol{F}$ were specifically blocked by FM1-43 application into the OV.

in nucleus magnocellularis of the developing chicken: an electron microscope study. Neuroscience 7:855-870.

Jones TA, Jones SM, Paggett KC (2006) Emergence of hearing in the chicken embryo. J Neurophysiol 96:128-141.

Kawakami K (2005) Transposon tools and methods in zebrafish. Dev Dyn 234:244-254.

Kimmel CB, Hatta K, Metcalfe WK (1990) Early axonal contacts during development of an identified dendrite in the brain of the zebrafish. Neuron 4:535-545.

Kimmel CB, Ballard WW, Kimmel SR, Ullmann B, Schilling TF (1995) Stages of embryonic development of the zebrafish. Dev Dyn 203:253-310.

Kimura Y, Okamura Y, Higashijima S (2006) alx, a zebrafish homolog of Chx10, marks ipsilateral descending excitatory interneurons that participate in the regulation of spinal locomotor circuits. J Neurosci 26:5684-5697.

Kohashi T, Oda Y (2008) Initiation of mauthner- or non-mauthnermediated fast escape evoked by different modes of sensory input. J Neurosci 28:10641-10653.

Lenoir M, Shnerson A, Pujol R (1980) Cochlear receptor development in the rat with emphasis on synaptogenesis. Anat Embryol (Berl) 160:253-262.

Limb CJ, Ryugo DK (2000) Development of primary axosomatic endings in 
the anteroventral cochlear nucleus of mice. J Assoc Res Otolaryngol 1:103-119.

Lin JW, Faber DS (1988) Synaptic transmission mediated by single club endings on the goldfish Mauthner cell. I. Characteristics of electrotonic and chemical postsynaptic potentials. J Neurosci 8:1302-1312.

Meyers JR, MacDonald RB, Duggan A, Lenzi D, Standaert DG, Corwin JT, Corey DP (2003) Lighting up the senses: FM1-43 loading of sensory cells through nonselective ion channels. J Neurosci 23:4054-4065.

Mikaelian D, Ruben RJ (1965) Development of hearing in the normal CBA-J mouse. Acta Otolaryngol 59:451-461.

Nakajima Y (1974) Fine structure of the synaptic endings on the Mauthner cell of the goldfish. J Comp Neurol 156:379-402.

Nakayama H, Oda Y (2004) Common sensory inputs and differential excitability of segmentally homologous reticulospinal neurons in the hindbrain. J Neurosci 24:3199-3209.

Neises GR, Mattox DE, Gulley RL (1982) The maturation of the end bulb of Held in the rat anteroventral cochlear nucleus. Anat Rec 204:271-279.

Obholzer N, Wolfson S, Trapani JG, Mo W, Nechiporuk A, Busch-Nentwich E, Seiler C, Sidi S, Söllner C, Duncan RN, Boehland A, Nicolson T (2008) Vesicular glutamate transporter 3 is required for synaptic transmission in zebrafish hair cells. J Neurosci 28:2110-2118.

Oda Y, Kawasaki K, Morita M, Korn H, Matsui H (1998) Inhibitory longterm potentiation underlies auditory conditioning of goldfish escape behaviour. Nature 394:182-185.

Omori Y, Malicki J (2006) oko meduzy and related crumbs genes are determinants of apical cell features in the vertebrate embryo. Curr Biol 16:945-957.

Popper AN, Fay RR (1993) Sound detection and processing by fish: critical review and major research questions. Brain Behav Evol 41:14-38.

Popper AN, Fay RR (1999) The auditory periphery in fishes. In: Comparative hearing: fish and amphibians, pp 43-100. New York: Springer.

Prober DA, Zimmerman S, Myers BR, McDermott BM Jr, Kim SH, Caron S, Rihel J, Solnica-Krezel L, Julius D, Hudspeth AJ, Schier AF (2008) Zebrafish TRPA1 channels are required for chemosensation but not for thermosensation or mechanosensory hair cell function. J Neurosci 28:10102-10110.

Riley BB, Zhu C, Janetopoulos C, Aufderheide KJ (1997) A critical period of ear development controlled by distinct populations of ciliated cells in the zebrafish. Dev Biol 191:191-201.

Seiler C, Ben-David O, Sidi S, Hendrich O, Rusch A, Burnside B, Avraham $\mathrm{KB}$, Nicolson T (2004) Myosin VI is required for structural integrity of the apical surface of sensory hair cells in zebrafish. Dev Biol 272:328-338.

Seiler C, Finger-Baier KC, Rinner O, Makhankov YV, Schwarz H, Neuhauss SC, Nicolson T (2005) Duplicated genes with split functions: independent roles of protocadherin 15 orthologues in zebrafish hearing and vision. Development 132:615-623.

Shin JB, Adams D, Paukert M, Siba M, Sidi S, Levin M, Gillespie PG, Gründer S (2005) Xenopus TRPN1 (NOMPC) localizes to microtubule-based cilia in epithelial cells, including inner-ear hair cells. Proc Natl Acad Sci U S A 102:12572-12577.

Sidi S, Friedrich RW, Nicolson T (2003) NompC TRP channel required for vertebrate sensory hair cell mechanotransduction. Science 301:96-99.

Sidi S, Busch-Nentwich E, Friedrich R, Schoenberger U, Nicolson T (2004) gemini encodes a zebrafish L-type calcium channel that localizes at sensory hair cell ribbon synapses. J Neurosci 24:4213-4223.

Sobkowicz HM, Rose JE, Scott GE, Slapnick SM (1982) Ribbon synapses in the developing intact and cultured organ of Corti in the mouse. J Neurosci 2:942-957.

Söllner C, Rauch GJ, Siemens J, Geisler R, Schuster SC, Müller U, Nicolson T (2004) Mutations in cadherin 23 affect tip links in zebrafish sensory hair cells. Nature 428:955-959.

Szabo TM, Weiss SA, Faber DS, Preuss T (2006) Representation of auditory signals in the M-cell: role of electrical synapses. J Neurophysiol 95:2617-2629.

Szabo TM, McCormick CA, Faber DS (2007) Otolith endorgan input to the Mauthner neuron in the goldfish. J Comp Neurol 505:511-525.

Uemura O, Okada Y, Ando H, Guedj M, Higashijima S, Shimazaki T, Chino $\mathrm{N}$, Okano H, Okamoto H (2005) Comparative functional genomics revealed conservation and diversification of three enhancers of the isl1 gene for motor and sensory neuron-specific expression. Dev Biol 278:587-606.

Whitehead MC, Morest DK (1985) The development of innervation patterns in the avian cochlea. Neuroscience 14:255-276.

Zottoli SJ (1977) Correlation of the startle reflex and Mauthner cell auditory responses in unrestrained goldfish. J Exp Biol 66:243-254. 